\title{
Ayudando a Una LobaSolitaria y Su Cub Moribundo: Helping a Lone Wolf and Her Dying Cub
}

\author{
Dawn Loshigian and Nadira T. Pardo \\ California Southern University, Irvine CA, USA
}

\begin{abstract}
The purpose of this article is to describe the experience of a young, single, Latina parent whose child has died as a result of a rare, terminal genetic defect in the context of a long standing friendship. The article examines the communication of an effective bereavement counselor as well as seeks to explore the systematic steps parents could employ to help their children with life limiting illnesses including treatment, palliative care, removing life support, hospice, and managing personal grief. Finally, special considerations were made to be sensitive to pertinent multicultural and spiritual or religious aspects that may be evident in the unique world of parents who have lost a child.
\end{abstract}

Key words: Death of a child, parents, Hispanics, grief, mourning, bereavement.

\section{Introduction}

December 15, 2014. 4:00 p.m. The telephone rings. Dawn: Hello?

Maria: I am so glad you're home (hurriedly)...I just got off the phone with Abuelita, Juan's Mama, in Mexico. I went to the doctor today, and he had the MRI results I have been waiting for to address Diego's headaches and seizures. The doctor said that he has something called Cerebral Cavernous Malformation or CCM1. It is a rare disorder that causes angiomas o grupos de vasossanguíneos que causanpresión o sangradoen el cerebro y la médulaespinal. Enalgunas personas, puedensertratados. Sin embargo, Diego tienetresangiomasinaccesiblesen el vástago de cerebro. En el mejor de loscasospodemosesperarconvulsiones y fuertesdolores de cabeza. En el peor de loscasos, puedenaumentarentamaño y la ruptura. Como resultado, élpuedetenerunaccidente cerebrovascular con déficitsneurológicos o enestadovegetativodebido a daño de cerebrosevero. Aunque no es fatal para todos, el doctor dijo que

Corresponding author: Nadira T. Pardo, professor, Ph.D., research field: psychology. seguramentemorirácomolosangiomas son de tamañosignificativo e inoperable. Tambiéndijo que estaenfermedadafectadesproporcionadamente a loshispanos, especialmentemexicanos de nuevo México debido a unamutacióngenéticaespecífica. Me preguntósobre mi familia... Como ustedessaben, Juan murióeneseaccidente fatal debido a un aneurisma que tuvomientrasconducía a su casa. El doctor piensa que puedesermás probable que éltambiéntenía CCM1 así. Élestabapreguntandosobre $\mathrm{mi}$ historialmédico, asícomo la de Pablo. Ah, estoesmás de lo que puedosoportarahora... Apenaspuedomantenerme con las cuentascomoes!

Dawn: Whoa! Slow down Maria! My Spanish is kind of rusty. Can you tell me in English please?

Maria: Oh, I am so sorry. It's harder for me to communicate in English. When I am upset, I always revert back to Spanish. The disease causes angiomas or groups of blood vessels that cause pressure or bleeding in the brain and in the spinal cord [1]. In some people, they can be treated. However, Diego has three inaccessible angiomas in the brain stem [2]. At best, we can expect severe headaches and seizures. At worst, they can increase in size and rupture. As a result, he may have a stroke with neurological deficits 
or be in a vegetative state due to severe brain damage [2]. Although it is not fatal for everyone, the doctor said that he will most likely die as the angiomas are of significant size and inoperable [1]. He also said that this disease disproportionately affects Hispanics, especially Mexicans from New Mexico because of a specific genetic mutation [3]. He asked me about my family...As you know, Juan died in that fatal car crash due to an aneurysm he had while he was driving home. The doctor thinks that it may be more likely that he also had CCM1 as well [4]. He was asking about my medical history as well as Pablo's. Ah, this is more than I can bear now...I can hardly keep up with the bills as it is!

I have been friends with Maria for a little over a decade now, and I remember the toll it took on her and the boys when Juan died suddenly; the shock, sadness, and fear were overwhelming for her. At four and six, the boys were confused by what had happened, but they believed that their father would return. Since then, Maria has been struggling to make a life for her sons. It hasn't been easy, but they have been able to live in a decent borough of New York City. It's an area with a large Mexican population so she feels comfortable there since moving from the state of New Mexico eleven years ago. She wanted to send her sons to the school at her church, but she could not because of finances. However, she was able to get the boys into a pretty good elementary school in the area. To date, she works nights as an environmental tech at a hospital a few blocks from her apartment. She has also been picking up extra day shifts as a food server at a near by Mexican restaurant when she is not scheduled at the hospital. I don't think I have ever seen her well-rested in years; there are always black circles under her eyes. However, she always enjoys the Spanish mass at the local Catholic Church at 10:30 on Sunday mornings. She doesn't have much in the way of family here in the city; an older lady in her apartment building tucks her boys in bed at night. Because she is my good friend, I must make an effort to help her.

\section{Talking to a Parent Whose Child is Dying}

Clinician or not, there are certain ways to help a parent whose child is dying. Remer, a clinical social worker, recommends helping parents over an extended period of time with support that is constructive, positive, and most importantly, empowering [5]. This allows parents to make decisions and take control of the situation to the degree that they can which results in greater coping. In addition, she suggests that helpers seek to establish strong rapport with parents. She defines this as "the pattern of communication that develops after demonstrating feelings of interest, understanding, and genuine concern for another. Conveying respect, caring, and being non-judgmental are necessary ingredients for building rapport" (p. 8). When helpers build rapport with parents, trust develops and healing can begin. Finally, helpers should be mindful of their personal boundaries and limits to help solve issues. Kaplan (2000), as cited by Becvar, explains that it would be easy to become overly absorbed [6].

\section{Communication Basics}

There are some basic communication elements which may prove useful. Remer suggests that the helper listen actively and employ empathy by attending through verbal and nonverbal methods, paraphrasing, reflecting content, and allowing for a safe space for people to share difficult emotions, to cry, or to be angry [5]. Helpers should listen without judgment, be present, follow the lead of the family, avoid small talk, allow for silence, look at pictures of the child (if offered), talk about special memories and even laugh [5]. Most importantly, helpers must affirm the feelings and emotions of the grieving parents. For example, helpers might make supportive statements such as: "Your reactions are normal", "I am sorry this happened to your child", or "you are doing the best you can under very difficult circumstances" (p. 13). Conversely, there is communication that is counterproductive or should be avoided. According to Remer, helpers should not 
tell the family what they should be doing or how they should be feeling, attempt to make decisions for them, deny expressions of grief, impose their personal beliefs or values, or focus on themselves [5]; she asserts that the helper should never say: "It could be worse", "it will pass", or "at least, you have another child" (p. 14-15). In situations such as these, there are so many questions and uncertainties. Although the doctor did indicate that Diego had a life-limiting illness, others have been more fortunate. Maria has the sole and daunting task of gathering all of the necessary information and making life and death decisions for her son.

\section{Beginning the Journey}

The first step is helping a child with a serious illness is to become educated. Maria, as Diego's advocate, must learn all she can about his disease. Sometimes that involves getting more than one professional opinion. She should also investigate possible sites to receive treatment. Although the hospitals in New York City and the surrounding areas have a strong reputation, she might want to consider other hospitals that specialize in these cases [4]. The most common test for this disorder is magnetic resonance imaging (MRI), but other imaging tests such as a CAT scan may be ordered. The condition is also managed with drugs and surgery (when appropriate). Because Diego is not a candidate for curative therapies, his pain and difficult symptoms will be managed with palliative care.

\subsection{Palliative Care}

Palliative treatments are a type of care meant to improve the quality of life for those with life-limiting, chronic, or terminal illnesses. The alleviation of pain and suffering is central to palliative care. According to Widger and Wilkins, there are elements that contribute to quality palliative or end of life care [7]; they include honest communication that provides parents (or the extended family) with a sense of understanding and decision making capacity, knowing what to expect when death comes, bereavement counseling and follow-up contact, caring and competent professionals who listen and collaborate, sibling support, appropriate symptom and pain management, addressing psychosocial or spiritual needs of the child, accessibility, respite care, and clear communication about financial arrangements, which may prove difficult in the face of an ongoing grave health concerns.

\subsection{Removing Life Support Measures}

Diego has three large, inoperable angiomas in the brain stem (where the spinal cord attaches to the brain). A hemorrhagic stroke in this area could lead immediate death or damage the brain stem, which controls vital functions such as breathing, heart rate, swallowing, and other involuntary functions [8]. According to the Minneapolis Clinic for Neurology [9], “(A) hemorrhage size of 60 cubic centimeters has an estimated 30-day mortality rate of $91 \%$. Patients with a hemorrhage volume of $30 \mathrm{cc}$ or more were severely disabled at 30 days. Hemorrhage into the lower brain region...carries a grave prognosis, with $55 \%$ mortality and $24 \%$ dependency in survivors. Hemorrhage into other locations may have a much better prognosis for survival and independence" [para 8].

Death could be imminent; however, there is the possibility that the impact of the rupture could cause severe brain damage with neurological deficits or rarer still, a vegetative state and death at some later date [2].

As a result, Maria and the healthcare team would then be faced with assessing Diego's likelihood of recovery, his quality of life, and whether or not life sustaining measures such as $g$ tubes, ventilators, and cardiovascular or renal supports should be employed and for how long. According to Levi, withdrawal of life supports such as nutrition and hydration should be presented in clear language, without pressure, and be conducted as a team approach rather than through a solitary individual [10]. Removal of life supports, including withdrawal of nutrition and hydration, is warranted in some cases, legally and ethically 
appropriate; even thoughth is difficult to discuss, it does not remove the team's responsibility to consider these viable options with parents [10].

\subsection{Hospice Care}

Because Diego's illness may be terminal, he may require hospice care. Hospice, a type of palliative care, is not a place but a way of delivering quality of life to those who have less than six months to live, have stopped curative treatments, or can have treatment at home. It is an alternative to a less medicalized hospital-based death. Normally, parents are the primary caregivers, but they are trained and supervised by an interdisciplinary team (IDT). The IDT will create a tailored treatment plan, assess the situation, make adjustments as necessary, and visit to check the patient's progress. A team consists of physicians, nurses of all types, social workers, chaplains, and home health aides; they are available around the clock. Normally, care is delivered at home, but the patient may also receive inpatient care for more serious symptoms. Supports are available for parents and families as well.

McKay, Taylor, and Armstrong conducted a study of "Hospice at Home" (HaH) programs in Ireland to determine the primary caretaker's experiences [11]. Although primary caretakers appreciated the support that they received through hospice, they commented that it was important for them to have a voice on the treatment team, for greater understanding of the challenge of managing medical/pharmaceutical protocols as laypeople, and communication to be accessible in a variety of formats for those who lack literacy [11]. Concerning Maria's case, perhaps it could be extrapolated that this support should be enhanced for those who lack social supports and make provision for those with limited English proficiency.

\subsection{Psychological Support: "Pack Mentality"}

Sickness and death can come without warning. It is especially difficult for low income, single parents to help their children with a serious, terminal diseases. In situations such as these, it is important to rally family and friends in order to be a listening ear, offer advice, run logistics, and even pray. However, Maria likes to talk with me from time to time about her issues because of my experience as a counselor who mainly works with children and adolescents. However, we are friends and are not in a clinical, therapeutic relationship. The American Counseling Association's Code of Ethicswarns, "Counselors are prohibited from engaging in counseling relationships with friends or family members with whom they have an inability to remain objective" (A.5.d.) [12].

As a result, I could not act as Maria's counselor in an official capacity, but I could suggest someone else as her concerned friend. Linda, a Latina clinical social worker, is well versed in handling family trauma and practices in Maria's neighborhood. She might be a good option if Maria and Pablo want to work with a professional counselor at this point or down the road. Although some would not consider a family therapist as an optimal choice for delving into end of life issues, Becvar argues that the family clinician may have an added dimension of insight [6]. This may include a greater understanding of family dynamics, systems theory, and the ability to spend more time with their clients [6]. Death does not occur in a vacuum; it is very much a "family affair".

\subsection{Peace of Mind for Maria}

In Maria's case, there are some additional talking points. Her first language is Spanish; although she is bi-lingual, she finds it easier to think and communicate in Spanish. Although she may not always have access to people who can speak her language, a counselor who is a native speaker may be comforting. Diego's terminal illness also may resurface emotions concerning Juan's relatively recent death. A helper must be mindful that old trauma may need to be re-processed. In addition, because this is a genetic disorder, Maria may feel responsible or at fault as well 
as have concerns for herself and her older son Pablo. As her doctor implied, she may need to be evaluated by a genetic counselor to learn if she or Pablo is at future risk [1]. According to Daitz, each child of an affected parent has a $50 \%$ chance of getting this autosomal disease [2]. If so, she would need not only to make the proper medical arrangements, but also consider a caretaker for Pablo (in the event she was incapacitated), life insurance, a will, and advance directives with a healthcare proxy. A support group for parents coping with children with rare terminal illnesses might also be a good way to talk about what the family is facing.

\section{The Lone Wolf and Caretaking}

\subsection{Special Risk Factors}

Becker and colleagues assert that after a death in the family, people may experience distress, PTSD like symptoms, and depression [13]. Although depression can be influenced by a myriad of factors including genetics (e.g. gender, family predisposition, etc.), environmental or social factors, and other items, a significant trauma such as the loss of her son (preceded by the relatively recent loss of her husband) combined with a lack of social support and the financial strain of her son's terminal illness could make "the perfect storm" for Maria to have a mental health crisis-despite her young age of 32. According to the American Psychological Association [14], "Women of color are more likely than Caucasian women to share a number of socioeconomic risk factors for depression, including racial/ethnic discrimination, lower educational and income levels, segregation into low status and high-stress jobs, unemployment, poor health, larger family sizes, marital dissolution, and single parenthood" (para 7).

\subsection{Hopelessness, Resilience, and the Mexican Female}

Caring for a child with a chronic, life limiting illness is daunting. Maria has additional challenges in that she is single and has limited social, financial, and other resources. It would be understandable for a feeling of hopelessness to set in over the days, weeks, and months of Diego's terminal illness. Marsiglia and colleagues studied hopelessness among low-income Mexican-heritage mothers in the Southwest; they chose women because they were more likely to experience psychiatric disorders such as anxiety and depression when compared to men [15]. They hypothesized that lack of social support and family stressors (such as family conflict or lack of resources) would be associated with higher levels of hopelessness and depression [15]. Hopelessness was defined as feeling that negative experiences were inevitable and positive items not possible of developing; the prevalence of hopelessness is higher in immigrant women due to increased environmental stressors [15].

Hopelessness can be a key component in some forms of depression; according to Alegria et al., as cited by Marsiglia, depression is one of the most common psychological disorders among Latinos [15]. However, some degree of hopelessness (or fatalism) can serve as a coping mechanism or protective barrier for some Hispanics [15]. In addition, a lack of social support can lead to hopelessness and possible depression in the face of hardship or adversity. Marsiglia et al. commented that "This is especially relevant among Mexican heritage Latinos...living in the United States because they may not have family residing close by because of immigration, and they may not find friends who have common beliefs and values" (p. 9) [15]. The study demonstrated that familial support and having a source of employment did in fact promote greater hope and resilience; theyrecommended that clinicians examine hopelessness from a multicultural perspective, acknowledge that increased levels of hopelessness may lead to depression for some, be aware that the immigration process can cause added stress for Latinas, and that talking about depression or hopelessness may be undesirable in certain Latino populations [15].

\section{If Her Cub Should Wake No More}

\subsection{The World of a Bereaved Parent}

Losing a loved one is never easy, but parents who 
lose children may endure a life of unrelenting pain as the death of a child reverses the natural order of things. Not unlike other survivors, grief-stricken parents may experience physical problems, psychological upset or disorders, and existential crises about who they are, what they value, and how the world works [16]. Li, Laursen, Precht, Olsen, and Mortensen, as referenced by Rogers and colleagues, found that bereaved mothers were at greater risk of a psychiatric hospitalization when compared to non-bereaved parents; maternal risk for hospitalization remains elevated even five or more years later [17]. In addition, maternal grief was associated with greater illness possibly from stress, immunological vulnerability, and unhealthy coping behaviors such as drug use [17]. Finally, Lesher and Berger, as cited by Malkinson and Bar-Tur, commented that bereaved elderly mothers suffered from note-worthy psychological distress-especially in the face of an adult child's death [18].

Woodgate, who studied parental bereavement, found that parents never fully recover from the experience and asserted, "Most important was the finding that in moving forward, parents did not experience a sense of closure. Not only did parents live in a world without closure, but they did not seek closure as that was associated with ending their relationship with their child" (p. 77-78) [16].

Woodgate describes their new world without closure with four distinct themes: Memory making, being a good parent, being present at the child's death, and "being there for me" after the child passes [16]. Positive memories were useful in helping parents live without closure; however, parents who missed out on happy times with their children expressed regret. Parents continued memory making by creating rituals on special days (e.g. the child's birthday), cherishing special objects related to the child, sensing the child's spirit, internally talking with the child, and sharing memories with close family and friends [16].

There were other items that brought parents relief and consolation. Parents who believed that they were good parents were better able to tolerate a life without closure [16]. Good parents were defined in the study as people who did everything humanly possible to help and support their child's health and happiness; Woodgate described this as being physically present, offering emotional support, and being an effective advocate; she suggests that parents create a "legacy document" that describes what they felt most proud of as parents, their own personal strengths, and the child's special history [16]. In addition, the ultimate expression of being a good parent could be seen in parents who were able to be present and contribute in a meaningful way at their child's death [16]. It is important for medical personnel to not to rob parents of this important contribution (i.e. the last act of caretaking), but remember that parents must be valued as equal members of the treatment team. Caretakers can also support parents by being available (if possible) when the child is actively dying as familiar faces are more comforting and maintaining a connection with the family after the child has passed [16].

The old adage states that "time heals all wounds," however, bereavement can plague people throughout the lifespan. Rogers et al. found that grief-stricken parents have more health issues, psychological problems, marital issues and the like well into middle age [17]. However, bereavement persists into old age as well.Malkinson and Bar-Tur, who studied elderly parents who lost their children, assert that the death of others is a reminder of their personal pain and grief [18]. One participant commented, "It's like a heavy burden. We can never put it down. It becomes heavier and heavier" (p. 425) [18].

Although there really is no closure for bereaved parents, what it means to lose a child can flex and change over time. According to Malkinson and Bar-Tur, "The bereavement process is therefore regarded as an accommodation rather than recovery, closure, or resolution" (p. 415) [18]. Although status may vary in a person's life, parenthood is for life; a person is no longer a parent when the person dies ( $p$. 
416) [18]. Bereaved parents must learn new ways to interact with the deceased as well as to cope over the course of their lives. They also have the important task of coming to terms with the death of their child as well as finding their own special purpose [17].

\subsection{Religion and Spirituality in Mourning: The Process and Results}

It is no surprise that religion and spirituality are beneficial for consolation and understanding extreme loss [13, 19]. According to Scneidman, as referenced by Marrone, "Mourning is one of the most profound human experiences... The deep capacity to weep for the loss of a loved one and to continue to treasure the memory of that loss is one of our noblest human traits" (p. 503) [19]. Marrone explored the role of spirituality during mourning [19]. Although many theorists have different ways to explain this, there are four essential elements that are common to all; these involve cognitive restructuring (the loved one is no longer in this world), emotional expression, integrating new coping skills, and for some, psycho-spiritual changes [19].

Surprisingly, not everyone relates negative aspects to mourning. Spirituality may also reveal hidden joys in the mourning experience; Kessler, as cited by Marrone commented that some mourners expressed some level of relief or freedom from various experiences or difficulties [19]. In addition, Wortman, as noted by Marrone, found religious and spiritual beliefs helped parents not only to find meaning in a child's death, but were indirectly related to less distress among parents 18 months later [19]. Finally, Becker et al. conducted research study the relationship of spirituality and grief through a systematic review [13]. Although the findings were varied, Thearle and colleagues, as referenced by Becker et al., studied 260 families after the loss of a child and found that bereaved parents who attended church regularly had less depression and anxiety [13]. Despite the fact that there is some evidence to support that religion and spirituality are helpful during times of acute grief and mourning, Becker et al. cautioned that there were limitations in that many of the research studies tended to feature Caucasian, Protestant, females in the United States [13].

\subsection{Culture, Religion and Death}

Maria's ancestors immigrated to the United States in search of a better life. Maria married Juan at 21, grew up in the State of New Mexico, and moved to NY. She has been living in the city since 2005 . At 32 , she has ingrained traditions and customs from her Latina heritage as well as beliefs from mainline Catholicism. However, suppose Maria were Asian American? How would her culture affect her views on mourning and death?

Braun and Nichols conducted a study to explore this in Asian American cultures [20]. There are interesting differences worth considering. For example, Mexicans verbally celebrate and honor the dead [20]. However, Wilson and Ryan, as cited by Braun and Nichols, asserted the Chinese refrain from even talking about death and consider it "bad luck" (p. 328) [20].Mexicans also believe that the dead return at least once a year; it is a happy occasion, but not all cultures believe that a spirit's return is a good thing. According to Ryan, as cited by Braun and Nichols, if a person is not buried appropriately, he or she may return to harm the family [20]. In our example,Maria is a Catholic, however, many Asian Americans practice Buddhism. Although many Catholics believe in a progressive form of salvation (God's grace plus service plus participation in the sacraments), many Buddhists believe that one must be good in this life to be elevated in the next through reincarnation [20]. Many Christians, in general, recognize that people live in a world with evil and that bad things happen such as death. However, in the Vietnamese culture, children may die because they are paying for errors in a past life or evil behavior within the family [20]. Japanese Buddhists also believe in karma (i.e. what comes around, goes around), but 
they take a more social rather than individual view of suffering and misfortunes [20]. Despite the fact that death is universal, religion and culture often shape how people respond to it.

\section{The Conclusion without Closure}

June 1, 2016. 4:00 p.m. The telephone rings.

Maria: Dawn? Hi it's Maria. I wanted to call and let you know that Diego passed away this morning and...

Dawn: Oh! Maria, I am so sorry. How difficult it must...

Maria: Es okay. Really (pause). It's okay. Diego died peacefully at home after he had the stroke. He was not in any pain. Linda told me about hospice care. They were really great. They helped me know what to do and explained everything really well. Our nurse happened to be here when it happened...I just want to let you know that the visiting hours will be at the Spanish funeral home on the corner Friday and Saturday from 2-4 and 7-9. The funeral mass will be on Monday at 9 a.m. at my church. After we get back from the cemetery, my boss at the restaurant arranged for us to have lunch there.

Dawn: Thanks for letting me know. Let me know what I can do to help.

Maria: I hope you can make it. I feel like I have not seen you (or anyone else) for so long.

\section{Author's Caveat}

The names of people and organizations within this paper are fictional, and although they may resemble or be real entities in the world, this paper is intended as a teaching device to raise awareness of the issues, so all opinions related to the fictitious names of people and organizations should not reflect upon anyone who has a similar name as it is not the intention of the author to make any opinions about any real entities that may exist with similar namesakes.

\section{References}

[1] Cerebral Cavernous Malformation. (2012). NIH: Genetics Home Reference. Retrieved from https://ghr.nlm.nih. gov/condition/cerebral-cavernous-malformation.

[2] Daitz, B. (2007). Heirs to a rare legacy in New Mexico. Retrieved

from http://www.nytimes.com/2007/09/04/health/04gene.html.

[3] Fox News Latino. (2013). Rare brain disorder plagues New Mexico Hispanics. Retrieved from http://atino.foxnews.com/latino/health/2013/07/31/rare-b rain-disorder-plagues-new- mexico-hispanics/.

[4] Athone, T. (2013). New Mexico's colonial history offers clues to a rare genetic disease. Retrieved from http://www.fronterasdesk.org/content/new-mexico\%E2\% $80 \% 99$ s-colonial-history-offers-clues-rare-genetic-diseas e.

[5] Remer, M.M. (2007). Talking with someone whose child is dying: A guide for the short-term helper. Rolla, MO: Stonehaven Place.

[6] Becvar, D. S. (2003). The impact on the family therapist of a focus on death, dying, and bereavement. Journal of Marital and Family Therapy, 29 (4), 469-77. Retrieved from

http://proxy1.calsouthern.edu/login?url=http://search.proq uest.com.proxy1.calsouthern.edu/docview/220973304?ac countid $=35183$.

[7] Widger, K. A., \& Wilkins, K. (2004). What are the key components of quality perinatal and pediatric end-of-life care? A literature review. Journal of Palliative Care, 20 (2), 105-12. Retrieved from http://proxy1.calsouthern.edu/login?url=http://search.proq uest.com.proxy1.calsouthern.edu/docview/214199527?ac countid $=35183$.

[8] The Stroke Network. (2014). Stroke education. Retrieved from http://www.strokeeducation.info/brain/brainstem/.

[9] MCN Neurologists. (2014). Hemorrhagic stroke. Minneapolis Clinic of Neurology. Retrieved from $\mathrm{http} / / /$ minneapolisclinic.com/patient-resources/intracerebr al-hemorrhage-hemorrahagic-stroke/.

[10] Levi, B. H. (2003). Withdrawing nutrition and hydration from children: Legal, ethical, and professional issues. Clinical Pediatrics, 42 (2), 139-45. Retrieved from http://proxy1.calsouthern.edu/login?url=http://search.proq uest.com.proxy1.calsouthern.edu/docview/200093981?ac countid $=35183$.

[11] McKay, E. A., Taylor, A. E., \& Armstrong, C. (2013). "What she told us made the world of difference": Carers' perspectives on a hospice at home service. Journal of Palliative Care, 29 (3), 170-7. Retrieved from http://proxy1.calsouthern.edu/login?url=http://search.proq uest.com.proxy1.calsouthern.edu/docview/1442997932?a ccountid $=35183$.

[12] American Counseling Association. (2014). ACA Code of Ethics. Alexandria, VA: Author.

[13] Becker, G., Xander, C. J., Blum, H. E., Lutterbach, J., 
Momm, F., Gysels, M., \& Higginson, I. J. (2007). Do religious or spiritual beliefs influence bereavement? A systematic review. Palliative Medicine, 21 (3), 207-17. doi:http://dx.doi.org.proxy1.calsouthern.edu/10.1177/026 9216307077327.

[14] APA Fact Sheet. (n.d.). Women and depression. Retrieved from http://www.apa.org/about/gr/issues/women/depression.as px.

[15] Marsiglia, F. R., Kulis, S., Perez, H. G., \& Bermudez-Parsai, M. (2011). Hopelessness, family stress, and depression among mexican-heritage mothers in the southwest. Health \& Social Work, 36 (1), 7-18. Retrieved from http://proxy1.calsouthern.edu/login?url=http:// search.proquest.com.proxy1.calsouthern.edu/docview/85 7251197 ? accountid=35183.

[16] Woodgate, R. L. (2006). Living in a world without closure: Reality for parents who have experienced the death of a child. Journal of Palliative Care, 22 (2), 75-82. Retrieved from http://proxy1.calsouthern.edu/login?url=http://search.proq uest.com.proxyl.calsouthern.edu/docview/214214121?ac countid=35183.
[17] Rogers, C.H., Floyd, F.J., Seltzer, M.M., Greenberg, J., \& Hong, J. (2008). Long-term effects of the death of a child on parent's adjustment in midlife. Journal of Family $\begin{array}{llll}\text { Psychology, } & 22 & \text { (2), 203-211. }\end{array}$ doi:10-1037/0893-3200.22.2.203.

[18] Malkinson, R., \& Bar-Tur, L. (1999). The aging of grief in israel: A perspective of bereaved parents. Death Studies, 23 (5), 413-431. Retrieved from http://proxy1.calsouthern.edu/login?url=http://search.proq uest.com.proxy1.calsouthern.edu/docview/231389352?ac countid $=35183$.

[19] Marrone, R. (1999). Dying, mourning, and spirituality: A psychological perspective. Death Studies, 23 (6), 495-519. Retrieved from http://proxy1.calsouthern.edu/login?url=http://search.proq uest.com.proxy1.calsouthern.edu/docview/231407882?ac countid=35183.

[20] Braun, K. L., \& Nichols, R. (1997). Death and dying in four Asian American cultures: A descriptive study. Death Studies, $21 \quad$ (4), 327. Retrieved from http://proxy1.calsouthern.edu/login?url=http://search.proq uest.com.proxy1.calsouthern.edu/docview/231404932?ac countid $=35183$. 